Polymer Degradation and Stability

November 2016, Volume 133 Pages 404-412

http://dx.doi.org/10.1016/i.polymdegradstab.2016.09.001

http://archimer.ifremer.fr/doc/00350/46158/

(C) 2016 Published by Elsevier Ltd.

\title{
Modelling the non Fickian water absorption in polyamide 6
}

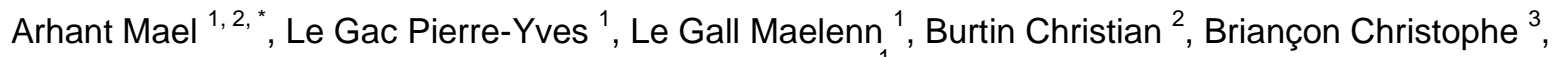 \\ Davies Peter ${ }^{1}$
}

1 IFREMER, Marine Structures Laboratory, Centre de Bretagne, F-29280, France

${ }^{2}$ Ecole Centrale de Nantes, Institut de Recherche en Génie Civil et Mécanique (GeM), F-44321, Nantes, France

${ }^{3}$ CETIM, Technocampus EMC2, F-44340, Bouguenais, France

* Corresponding author : Mael Arhant, email address : mael.arhant@ifremer.fr

\begin{abstract}
:
This paper investigates the water absorption of polyamide 6 . The high amount of absorbed water in the polymer and the large resulting decrease in the glass transition temperature $(\mathrm{Tg})$ leads to a non Fickian water diffusion when samples are immersed, which is a significant difficulty when trying to model the water profile in thick specimens. The aim of this study is to be able to model this particular behaviour based on physical considerations. First, it is shown that the non Fickian water diffusion is caused by an increase in the diffusivity during water absorption. Two cases are then identified; one below $\mathrm{Tg}$ where the diffusivity is described using an Arrhenius law and one above $\mathrm{Tg}$ based on the free volume theory. Then, these two laws are implemented in a specific model that is able to describe the non Fickian water diffusion over a wide range of temperatures.
\end{abstract}

Keywords : Water absorption, Free volume, Polyamide 6, Sea water, Modelling 


\section{Introduction}

Polyamides (PAs) are widely used in many engineering applications due to their very interesting mechanical properties and ease of processing, as they allow the injection of thick components with complex geometries. Moreover, they are candidates for lightweight and lowcost high performance structures when reinforced with fillers such as clay [1] or fibres [2], [3]. Reinforced polyamides are excellent candidates for underwater applications, as they can be easily repaired or reused. However, in such harsh environments, PA will undergo ageing during service that may limit its use.

The ageing mechanisms in PA are mainly induced by either a reaction of the polymer with oxygen (i.e. oxidation) [4], [5] or interaction with water. The latter has been widely studied in the past, and it has been shown that PA6 absorbs a large amount of water when immersed, up to $10 \%$ at $20^{\circ} \mathrm{C}$ [6]. This behaviour is related to the presence of polar groups $(\mathrm{NH})$ coupled with the formation of clusters at high water activities. The presence of water within the polymer leads to an increase in mobility of the macromolecular chains that is characterised by a decrease in the glass transition temperature $\left(\mathrm{T}_{\mathrm{g}}\right)$. Lim et al. [7] showed that the $\mathrm{T}_{\mathrm{g}}$ decreases from $60^{\circ} \mathrm{C}$ to $-10^{\circ} \mathrm{C}$ when $10 \%$ of water is absorbed. This phenomenon, plasticisation, induces large changes in the mechanical behaviour. For example, Reimschuessel [8] showed that the Young's Modulus decreases by a factor of 5 when $9 \%$ of water is absorbed. Moreover, the presence of water in PA6 can lead to a significant chemical degradation of the polymer. Amide groups react with water through a hydrolysis process [9] when immersed in water at high temperatures and/or for a long duration [10]. The latter leads to chain scissions that induce an embrittlement of the polymer and so lead to a large decrease in the mechanical properties. This irreversible reaction will not be considered in the present study, as exposure times were short enough to avoid this kind of degradation [11]. 
Despite the fact that the water absorption in PA6 has been widely studied in the literature in terms of mechanisms and consequences, there are still several open questions, and one concerns the modelling of the water diffusion process in the polymer. This modelling stage is absolutely necessary to evaluate the lifetime of thick structural parts. If it is not possible to predict the water diffusion and therefore the local water content throughout the thickness, it is not possible to predict accurately the loss in mechanical properties induced by water. In some studies, water absorption in PA6 immersed in water has been modelled using Fickian behaviour [12]-[14]. However, this description is clearly not accurate, as the Fickian behaviour is not conservative compared to experimental data. Thus, it should not be used when accurate predictions are required. This non-Fickian behaviour is explained by an increase in the water diffusion coefficient with the water content [15], [16] that occurs when the polymer is in the rubbery state [17]. Whereas the origin of the non Fickian behaviour is known, there is no accurate model based on physical considerations to describe the water absorption in PA6 when immersed in water. This is the aim of the present study.

\section{Materials and methods}

\subsection{Material}

The material of interest here is a polyamide 6 supplied by Goodfellow with a density of $1.13 \mathrm{~g} . \mathrm{cm}^{-3}$. It was received in the form of $2 \mathrm{~mm}$ thick panels processed by compression moulding. Polymer films of $70 \mu \mathrm{m}$ thickness were obtained from the latter with a Leica RM2245 microtome. Both thicknesses were used in this study. Polydispersity index and average molecular weight were measured by SEC and their values are respectively 2.5 and $48.1 \mathrm{~kg} / \mathrm{mol}$ with a degree of crystallinity $\chi$ of $38 \%$ (measured by DSC).

\subsection{Water absorption}


First, the water absorption in thick samples $(2 \mathrm{~mm})$ was determined from the weight changes of square samples $(50 \times 50 \times 2) \mathrm{mm}^{3}$ immersed at several temperatures. The different samples have been immersed in either natural renewed sea water from the Brest estuary or in deionised water. The mass gain was followed by periodic weighing of the different specimens on a Sartorius LA310 S balance having a precision of $0.1 \mathrm{mg}$. Before each measurement in immersion, the water on the surface of the specimen was wiped off with a paper towel. For each measurement, three samples were used at each time and the results averaged.

Dynamic Vapour Sorption (DVS) measurements were performed on Q5000 SA equipment from TA Instruments. The weight evolution of a $70 \mu \mathrm{m}$ polymer film contained within a humidity chamber (ranging from 0 to 0.9 water activity) was followed using a microbalance of $0.1 \mu \mathrm{g}$ resolution at various temperatures (from 15 to $80^{\circ} \mathrm{C}$ ). Again, for each condition, three samples were used.

For all conditions, the weight $\mathrm{M}(\mathrm{t})$ in $\%$ of a sample is defined as follows, Eq. 1:

$$
M(t)=\frac{W(t)-W_{0}}{W_{0}} \cdot 100
$$

Where $\mathrm{W}(\mathrm{t})$ is the mass of the sample at a time $\mathrm{t}$ and $\mathrm{W}_{0}$ the dry mass of the sample. It can be noted that prior to water exposure, all the samples were dried at $0 \%$ relative humidity at $40^{\circ} \mathrm{C}$ until their weight stabilised.

The relative mass ratio $w_{\mathrm{H}_{2} \mathrm{O}}$ and the relative volume ratio $v_{\mathrm{H}_{2} \mathrm{O}}$ are used to take into account the degree of crystallinity $\chi$ (respectively presented in Eq. 2 and Eq. 3):

$$
\begin{gathered}
w_{\mathrm{H}_{2} \mathrm{O}}=\frac{M(t)}{M(t)+(1-\chi) \cdot W_{0}} \\
v_{\mathrm{H}_{2} \mathrm{O}}=\frac{w_{\mathrm{H}_{2} O} \rho_{a}}{w_{\mathrm{H}_{2} \mathrm{O}} \rho_{a}+\left(1-w_{\mathrm{H}_{2} O}\right) \rho_{w}}
\end{gathered}
$$


Where $\rho_{\mathrm{a}}$ and $\rho_{\mathrm{w}}$ are respectively the densities of the amorphous phase of the polymer and water. Their values are taken to be equal to $1080 \mathrm{~kg} \mathrm{~m}^{-3}$ for $\rho_{\mathrm{a}}$ and $1000 \mathrm{~kg} \mathrm{~m}^{-3}$ for $\rho_{\mathrm{w}}$ [18].

\section{2. $T_{g}$ measurement}

After water absorption, dynamic mechanical analyses were performed on $\mathrm{DMA}^{+} 150 \mathrm{~N}$ equipment from Metravib to obtain the glass transition temperatures of the polymer. Measurements were made in tensile mode on samples of dimensions $(30 \times 15 \times 2) \mathrm{mm}^{3}$ tested at $2^{\circ} \mathrm{C} / \mathrm{min}$ over the temperature range from $-100^{\circ} \mathrm{C}$ to $150^{\circ} \mathrm{C}$. The static strain amplitude was $8 \times 10^{-4}$. The chosen frequency was $10 \mathrm{~Hz}$ and the dynamic strain amplitude was $2 \times 10^{-4}$. The glass transition temperature was taken to be the $\tan \delta$ peak. For each condition of interest, the samples were fully saturated in a thermo-hygrometric chamber (Servathin B204 3235) at different water activities at $80^{\circ} \mathrm{C}$ for 48 hours.

\subsection{Modelling}

The 2D model used in this study was developed using COMSOL Multiphysics 5.1 software. The square geometry considered was of $25 \mathrm{~mm}$ edge length and $1 \mathrm{~mm}$ thick with symmetry in all directions in order to simulate a $(50 \times 50 \times 2) \mathrm{mm}^{3}$ immersion coupon. A rectangular finite element mesh was used, with 50 elements in each direction, i.e. a mesh size of $0.5 \mathrm{~mm}$ by $0.02 \mathrm{~mm}$. Mesh size dependence was examined, and increasing or decreasing mesh size by a factor of 2 gave the same results.

\section{Results}

\subsection{Water absorption in $2 \mathrm{~mm}$ thick samples}

Immersion of thick specimens $(2 \mathrm{~mm})$ in water baths is considered here. First, the effect of temperature on the water absorption in sea water was investigated, Figure 1.a. 
Second, the effect of medium was examined, Figure 1.b. For both figures, the water content is plotted as a function of the square root of time divided by the sample thickness.

Figure 1 : (a) Water absorption in PA 6 immersed in sea water at several temperature (b) Effect of water type on $2 \mathrm{~mm}$ thick specimens at $25^{\circ} \mathrm{C}$

Figure 1.a shows that the polymer absorbs a significant amount of water when immersed in sea water, more than $10 \%$ at $15^{\circ} \mathrm{C}$ at saturation. This large water absorption is in accordance with existing results [6] and attributed to the high polarity of $\mathrm{NH}$ groups in the polymer. It also appears that the maximal water uptake decreases when the temperature increases due to a negative activation energy of the solubility. Temperature affects the water absorption kinetics; as expected the higher the temperature, the faster the water diffusion. This behaviour will be discussed in detail later.

Figure 1.b compares the water absorption in two different media: sea and deionised water. It clearly shows that the nature of the water affects both the maximal water uptake and water absorption rate, this can be explained by the fact that water activity in seawater is about 0.98 [20] i.e. lower than in deionised water. However, the overall trend is not affected.

In most polymers, water sorption follows a Fickian behaviour, the water diffusion can be described as follows using a diffusion coefficient $\mathrm{D}$ and a mass at saturation $\mathrm{M}_{\infty}$ [21], Eq. 4.

$$
\frac{M(t)}{M_{\infty}}=1-\frac{8}{\pi^{2}} \sum_{i} \frac{1}{(2 i+1)^{2}} \exp \left(-\frac{D(2 i+1)^{2} \pi^{2} t}{h^{2}}\right)
$$

Where $\mathrm{h}$ is the sample thickness in $\mathrm{mm}$ and the immersion time in $\mathrm{s}$.

The diffusion coefficient can be calculated from the initial linear part of the sorption curve where $\frac{M(t)}{M_{\infty}} \leq 0.5$, Eq. 5 . 


$$
D=\frac{\pi}{16} \cdot \frac{h^{2}}{t}\left(\frac{M(t)}{M_{\infty}}\right)^{2}
$$

The diffusion coefficient $\mathrm{D}$ and the mass at saturation $\mathrm{M}_{\infty}$ are identified on the experimental water sorption plot of $2 \mathrm{~mm}$ thick samples immersed at $15^{\circ} \mathrm{C}$ in sea water. These two values are then used to model a theoretical Fickian diffusion to be compared with the experimental data. Results are presented in Figure 2.

Figure 2 : Comparison between experimental results at $15^{\circ} \mathrm{C}$ in sea water and a Fickian behaviour with a D equal to $1.6 \times 10^{-13} \mathrm{~m}^{2} / \mathrm{s}$ (identified on the experimental data in the linear part of the sorption curve)

Figure 2 clearly shows that it is not possible to describe the water absorption in these polyamide polymers using the Fickian law. In fact, an increase in water content at the end of the sorption curve is observed compared to the Fick plot. This behaviour can be explained by an increase in the diffusion coefficient across the thickness of the specimen when the latter is in the rubbery state.

In order to investigate this particular behaviour over a wide range of temperatures and water activities, it was chosen to work with polymer films $(70 \mu \mathrm{m})$ using the DVS. The latter is very useful since saturating thick specimens at more than 15 different water activities per temperature would take years.

\subsection{Water absorption in thin films using DVS}

In the DVS, the sample is exposed to an environment at a given water activity and for a certain time until it reaches a plateau. After complete saturation, the water activity is increased by 0.05 and the same cycle is repeated again and again until an activity of a=0.9 is reached. An example of a DVS test conducted at $40^{\circ} \mathrm{C}$ is presented in Figure 3. Working with a small increase in the water activity allows samples to be obtained in which the water content varies slightly in the polymer. 
Figure 3 : Typical water absorption at $40^{\circ} \mathrm{C}$ as a function of water activity

At $a=0.9$, the polyamide matrix absorbs more than $8 \%$ of water $\left(\right.$ at $40^{\circ} \mathrm{C}$ ). From this test, each condition provides a mass at saturation that is plotted as a function of the water activity in Figure 4.

Figure 4 : Changes in the amount of absorbed water as a function of water activity at $25^{\circ} \mathrm{C}$

From this figure, it is clear that the water content increases linearly from $a=0.05$ to approximately a $=0.5$. Beyond this level, it deviates from linearity, which indicates that Henry's law is no longer verified. The deviation from Henry's behaviour is related to the formation of water clusters in the polymer at high water activities that can be described using a power law. This behaviour has been highlighted in the literature [22], [23]. It is possible to describe the amount of water absorbed in the polymer with Eq. 6 [23] that uses Henry's law in the linear part (at low water activities) and another part that is related to the formation of water clusters in the polymer at high water activities.

$$
M_{\infty}=H \cdot a+b \cdot a^{m}
$$

Where $\mathrm{a}$ is the water activity, $\mathrm{H}, \mathrm{b}$ and $\mathrm{m}$ are polymer characteristics. Broudin [24] showed that this equation was able to describe the maximal water sorption in Polyamide 6.6. It was shown that $\mathrm{H}$ could be represented by a typical Arrhenius law; here, the pre exponential factor $\mathrm{H}_{0}$ is equal to 0.38 and the activation energy $\mathrm{E}_{\mathrm{a}}$ is equal to $7 \mathrm{~kJ} / \mathrm{mol}$. $\mathrm{b}$ and $\mathrm{m}$ were found to be respectively equal to 4 and 3 and independent of the testing temperature. Now that the maximal water absorption for each humidity step has been considered, it is interesting to focus on the water absorption rate.

For each water sorption at a given water activity, a Fickian diffusion coefficient D was identified from the experimental data and the the Fickian equivalent was plotted at different water activities $(0.2,0.4,0.6$ and 0.8$)$, presented in Figure 5. 
Figure 5 : Normalized water absorption at $25^{\circ} \mathrm{C}$ as a function of water activity (a) a=0.2 (b)

$$
\mathrm{a}=0.4 \text { (c) } \mathrm{a}=0.6 \text { (d) } \mathrm{a}=0.8
$$

Figure 5 shows that in this case, the water absorption can be described based on Fickian behaviour for all the water activities at $25^{\circ} \mathrm{C}$. It has to be noted that the results in Figure 5 are not in contradiction with the results in Figure 2. In fact, as noted previously, a non Fickian behaviour is observed when dried thick samples are immersed in water. However, when very slight increases in water are used (DVS), it is possible to model the water uptake using the Fickian law with a given diffusion coefficient that changes with the water content (Figure 5 and Figure 6). The dependence of diffusivity on the water content can be neglected when very slight differences in water contents are considered. However, when large water content differences exist, the diffusion coefficient changes through the thickness, and this results in an overall non Fickian behaviour.

Showing that the water diffusion follows a Fickian diffusion at every water activity allows the diffusion coefficient $\mathrm{D}$ identified for each condition to be plotted as a function of the water activity. An example at $25^{\circ} \mathrm{C}$ is presented in Figure 6.

Figure 6 : Change in diffusivity as function of water activity in PA 6 (example at $25^{\circ} \mathrm{C}$ )

Results from Figure 6 show that the diffusion coefficient is stable (around $1.0 \times 10^{-13}$ $\mathrm{m}^{2} / \mathrm{s}$ ) at low activities and then increases up to a value of $6.5 \times 10^{-13} \mathrm{~m}^{2} / \mathrm{s}$ for higher activities. This behaviour is in agreement with the literature [15], [17], [21] and can be explained by the decrease in the glass transition temperature induced by plasticisation during water absorption. The changes in $\mathrm{T}_{\mathrm{g}}$ with water content will be considered in the next section.

\subsection{Changes in $T_{g}$ with water absorption}

It is well known that the water absorption leads to an increase in the chain mobility of the polymer and so to a decrease in the glass transition $\left(\mathrm{T}_{\mathrm{g}}\right)$. This decrease in $\mathrm{T}_{\mathrm{g}}$ has many 
consequences for both diffusivity and the mechanical properties. Thus, it is necessary to be able to evaluate and describe the $\mathrm{T}_{\mathrm{g}}$ changes induced by the presence of water.

Glass transition temperatures values from DMA performed on thick specimens with homogeneous water contents following saturation at different water amounts are presented in Figure 7. It should be remembered that each specimen was saturated at a given water activity for a maximum time of 48 hours. To prevent hydrolysis at this temperature, the samples were tested as soon as saturation was reached. Also, Bernstein [10] showed that a longer time of exposure is needed for hydrolysis to occur.

Figure 7 : Changes in $\mathrm{T}_{\mathrm{g}}$ with water content measured (points) and predicted (dotted line)

From this result, it is clear that there is a very significant decrease in $\mathrm{T}_{\mathrm{g}}$ from $66 \pm 1{ }^{\circ} \mathrm{C}$ in the dry state to $-9 \pm 1{ }^{\circ} \mathrm{C}$ when the specimen is fully saturated with $9 \%$ of water. As water enters the material, the glassy amorphous phase of the polymer goes into the rubbery state because of the increase in chain mobility (plasticisation). This result is in agreement with the literature [8] and can be described using the Simha-Boyer equation, which is a simplified version of the Kelley-Bueche equation [25]. This equation establishes a relationship, based on the free volume theory that relates the decrease in $\mathrm{T}_{\mathrm{g}}$ with the water content as described hereafter in Eq. 7 and Eq. 8.

$$
\begin{gathered}
\frac{1}{T_{g}}=\frac{1}{T_{g p}}+A v_{H_{2 O}} \\
A=\frac{1}{T_{g s}}-\frac{1}{T_{g p}}
\end{gathered}
$$

Where $T_{g}$ is the glass transition temperature of the polymer $(\mathrm{K}), \mathrm{T}_{\mathrm{gp}}$ is the polymer glass transition temperature in the dry state (measured to be $333 \mathrm{~K}$ by DMA), $\mathrm{T}_{\mathrm{gs}}$ is the glass transition of the solvent (here water) that is taken equal to $110 \mathrm{~K}$ [17] and $v_{\mathrm{H}_{2} \mathrm{O}}$ is the volume fraction of water in the polymer previously described in Eq. 4. The comparison between 
experimental results (points) and the Simha-Boyer equation (continuous line) in Figure 7 clearly shows that the decrease in $T_{g}$ induced by the presence of water can be accurately described, which is very useful for modelling.

To conclude on the experimental section, we have shown that Henry's law is not verified here, as at high water activities the formation of clusters is observed. This behaviour can be described using a simple mathematical equation (Eq. 6). In the meantime, using the DVS measurements with small humidity steps, it is possible to show that the water absorption in PA6 follows a Fickian behaviour for all the water activities. This also allows us to determine the diffusion coefficients for all these conditions. It appears that the diffusivity depends strongly on the water activity for a given temperature. At low activities, the diffusion coefficient is constant whereas at high activities, a large increase is observed. This behaviour is explained by the change from the glassy to the rubbery state of the amorphous phase of the PA6. The water absorption leads to a large decrease in $\mathrm{T}_{\mathrm{g}}$ that can be accurately described using the simple Simha-Boyer relationship. The description of these changes in water diffusivity with both temperature and water activity will considered in the next section.

\section{Discussion and Modelling}

In this section a new model is proposed that describes water absorption in thick polyamide 6 when used in a humid environment and more especially in sea water over a wide range of temperatures.

From the previous results, it is now possible to describe the water content at saturation when a specimen evolves at a given water activity (Eq.6). Then, it has been shown that from the latter, we can evaluate the $\mathrm{T}_{\mathrm{g}}$ for a given water content (Eq.7 and Eq.8). Above a certain water activity, the polymer goes into the rubbery state and we have seen that the behaviour is very different between the glassy and the rubbery state (Figure 4 and Figure 6). The current 
section will focus on predicting the diffusion coefficient below and above the glass transition of the polymer. First, the prediction of the diffusion coefficient below $\mathrm{T}_{\mathrm{g}}$ is made using an Arrhenius equation. Second, the free volume theory is used to describe the behaviour above $\mathrm{T}_{\mathrm{g}}$. Finally, these two laws are combined and used in a model to predict the water diffusion in a thick sample immersed in water at a given temperature and the prediction is compared to experimental data.

A schematic representation of the model is presented in Figure 8.

Figure 8 : Schematic representation of the model

The dry specimen is exposed to a given temperature and water activity (0) and water sorption starts. As water enters the polymer, the model is used to calculate the water content at a given position across the thickness of the polymer (1). Then, equation 7 is used to predict the local glass transition of the amorphous phase of the polymer (2). In the case where the predicted glass transition is higher than the test temperature, the diffusion coefficient is calculated using the Arrhenius law because the polymer is in its glassy state (3). However, when the latter is in the rubbery state $\left(3^{\prime}\right)$, i.e. when the glass transition is lower than the test temperature, the model uses the free volume theory to obtain D (4). Then, the model follows an iteration loop for all positions across the thickness and for every immersion time $t$ until complete saturation.

The following sections will present the experimental validations for the calculation of $\mathrm{D}$ both below and above $\mathrm{T}_{\mathrm{g}}$.

\subsection{Behaviour in the glassy state}

It was shown in Figure 6 and also in the literature [15], [17] that the water diffusivity does not depends on the water activity when the polymer is in glassy state. However the 
diffusion coefficient depends on the temperature. This temperature effect can be described using the Arrhenius law (Eq. 9) as shown in Figure 9.

$$
D_{\left(T<T_{g}\right)}=D_{0} \cdot \exp \left(-\frac{E_{a}}{R T}\right)
$$

Where $D_{(T<T g)}$ is the diffusion coefficient in the glassy state in $\mathrm{m}^{2} / \mathrm{s}, \mathrm{D}_{0}$ the pre exponential diffusion coefficient in $\mathrm{m}^{2} / \mathrm{s}, \mathrm{E}_{\mathrm{a}}$ the activation energy in the glassy state, $\mathrm{R}$ the gas constant equal to $8.31 \mathrm{~J} \cdot \mathrm{mol}^{-1} \cdot \mathrm{K}^{-1}$ and $\mathrm{T}$ the temperature in $\mathrm{K}$.

Figure 9 : Measured diffusion coefficient $\mathrm{D}$ as a function of 1/RT

The activation energy in the glassy state is $72 \mathrm{~kJ} / \mathrm{mol}$. For comparaison, Abacha et al. [12] measured an activation energy of $54 \mathrm{~kJ} / \mathrm{mol}$, which lies in the same range. Silva et al. [6] also found comparable values of $64 \mathrm{~kJ} / \mathrm{mol}$. Therefore, it is now possible to describe the diffusion coefficient below the $\mathrm{T}_{\mathrm{g}}$ of the polymer. The next section will focus on the prediction of the diffusion coefficient above the $T_{g}$.

\subsection{Behaviour in the rubbery state}

When the polyamide is in the rubbery state, the diffusivity increases strongly with the water activity as shown in Figure 6 and [17]. This section aims to describe the changes in diffusivity with water activity based on the free volume theory that basically considers an increase of the polymer volume due to hole formation when the polymer is above its $\mathrm{T}_{\mathrm{g}}$. The presence of these holes changes the diffusivity of water considerably. In this case, it has been shown by Vrentas [26] that the water diffusion coefficient can be described using the following equations (Eq.10 and Eq.11).

$$
\begin{gathered}
D_{(T>T g)}=D_{02} \cdot \exp \left(-\frac{E}{R T}\right) \cdot \exp \left(-\frac{\gamma \cdot\left(w_{1} \cdot \widehat{V_{1}^{*}}+\xi \cdot \mathrm{w}_{2} \cdot \widehat{V_{2}^{*}}\right)}{\widehat{V_{F H}}}\right) \\
\frac{\widehat{V_{F H}}}{\gamma}=\left(\frac{K_{11}}{\gamma}\right) \cdot w_{1} \cdot\left(K_{21}+T+T_{g 1}\right)+\left(\frac{K_{12}}{\gamma}\right) \cdot w_{2}\left(K_{22}+T-T_{g 2}\right)
\end{gathered}
$$


Where $D_{(\mathrm{T}>\mathrm{Tg})}$ is the diffusion coefficient above $\mathrm{T}_{\mathrm{g}}$ in $\mathrm{m}^{2} / \mathrm{s}, D_{02}$ is a pre-exponential factor in $\mathrm{m}^{2} / \mathrm{s}, \hat{V}_{1}^{*}$ is the critical local hole free volume required for a molecule of species 1 (water) to jump to a new position, $\hat{V}_{2}^{*}$ is the critical local hole free volume per gram of polymer required for the displacement of a jumping unit, $w_{1}$ is the mass fraction of component 1 (i.e. water), $w_{2}$ is the mass fraction of component $2, \xi$ is the ratio of the critical molar volume of the solvent jumping unit to the critical molar volume of the polymer jumping unit, $\gamma$ is an overlap factor (which should be between 0.5 and 1) introduced because the same free volume is available to more than one molecule. $\mathrm{E}$ is the energy per mole that a molecule needs to overcome attractive forces holding it to its neighbours. $\hat{V}_{F H}$ is the average hole free volume per gram of mixture and can be calculated with Equation 11 where $K_{11}$ and $K_{21}$ are free volume parameters for the solvent, here water, and $K_{12}$ and $K_{22}$ are free volume parameters for the polymer, $T_{g 1}$ is glass transition temperature of water, $T_{g 2}$ is glass transition temperature of polyamide 6 .

At the temperatures of the study, the specific hole free volume is relatively small and the diffusion is free volume dominated. Therefore, the energy E in Eq. 9 can be included in the pre exponential factor $\mathrm{D}_{02}$ [27]. This leads to Eq. 12 which states that the diffusion above $\mathrm{T}_{\mathrm{g}}$ is mainly dominated by free volume effects.

$$
D_{(T>T g)}=D_{02} \cdot \exp \left(-\frac{\gamma \cdot\left(w_{1} \cdot \widehat{V_{1}^{*}}+\xi \cdot w_{2} \cdot \widehat{V_{2}^{*}}\right)}{\widehat{V_{F H}}}\right)
$$

This equation can now be used to determine the diffusion coefficient above $T_{g}$. However, several parameters inside the exponential term still need to be determined. First, the parameters associated with the solvent, which is water here, are presented in Table 1 . These values are taken from the literature [28]. 
Table 1 : Values for Water, from [28]

Second, the parameters associated with the polymer must be determined as well.

The quantity $\xi$ is defined as follows, Eq. 13:

$$
\xi=\frac{V_{1}^{0}(0)}{V_{2}^{*}(j)}
$$

Where $\mathrm{V}_{1}{ }^{0}(0)$ is the molar volume of water and $\mathrm{V}_{2}{ }^{*}(\mathrm{j})$ is the molar volume of the polymer. To calculate the latter, Hong [28] showed that for $\mathrm{T}_{\mathrm{g}}>295 \mathrm{~K}$, Eq. 14 can be used.

$$
V_{2}^{*}(j)=0.6224 . T_{g}(K)-86.95 \quad \text { Eq. } 14
$$

In our case, $\mathrm{T}_{\mathrm{g}}(\mathrm{K})$ is equal to $333 \mathrm{~K}$. The determination of $\mathrm{V}_{2}{ }^{*}(\mathrm{j})$ allows us to determine several other parameters of interest, Eq. 15 :

$$
\frac{\gamma \cdot \widehat{V_{2}^{*}}}{K_{12}}=2.303 \cdot C_{1} \cdot C_{2}
$$

The parameter $\mathrm{K}_{22}$ is defined in Eq.16:

$$
K_{22}=C_{2}
$$

Eq. 16

The parameters $C_{1}$ and $C_{2}$ are taken from the literature [18] and are summarised in Table 2.

Table 2: Values for the polymer, from [18]

Once all the parameters in the exponential term of Eq. 12 are obtained, it is possible to plot in Figure 10 the diffusion coefficient of the polymer at a given temperature above $T_{g}$ as a function of the exponential term.

Figure 10 : Experimental values of $\mathrm{D}$ as a function of the exponential term

Figure 10 shows that the diffusion coefficient above $T_{g}$ (whatever the testing temperature) as a function of the exponential in the rubbery state can be represented to a first approximation by a linear relationship. Therefore, the diffusion in polyamide 6 can be described using the free volume theory with a $\mathrm{D}_{02}$ value of $5 \times 10^{-10} \mathrm{~m}^{2} / \mathrm{s}$. 
Let us now compare the experimental values of $\mathrm{D}$ with the different expressions presented earlier (above and below $\mathrm{T}_{\mathrm{g}}$ ). The results are presented in Figure 11 .

Figure 11 : Predicted diffusion coefficient versus the measured values of D.

Figure 11 shows that the free volume theory can be used to describe the evolution of $\mathrm{T}_{\mathrm{g}}$ and $\mathrm{D}$ during water absorption. Therefore, now that all the expressions required to model the water absorption have been validated (maximal water absorption, glass transition, diffusion coefficient), a prediction of the diffusion can be made for thick specimens immersed in sea water at different temperatures.

\subsection{Comparison modelling/experiments}

As a reminder, the model presented schematically in Figure 8 describes the diffusion behaviour for all positions across the thickness and for every immersion time until complete saturation for a given medium and a given temperature.

Results from the model are presented in Figure 12 together with the experimental data. For each figure, the water content inside a $2 \mathrm{~mm}$ thick specimen at a given temperature is plotted as a function of the square root of time divided by the sample thickness. The Fickian law identified on the experimental data is also presented to show the difference compared to the model proposed here.

Figure 12 : Comparison between experimental results obtained on $2 \mathrm{~mm}$ thick samples immersed in sea water and the specific model developed in this study as well as the Fickian equivalent for (a) $15^{\circ} \mathrm{C} \mathrm{(b)} 25^{\circ} \mathrm{C}$ (c) $40^{\circ} \mathrm{C}$ (d) $60^{\circ} \mathrm{C}$

The results show a good agreement between the model and the experimental data, and are much closer than the Fickian approach. The proposed Tg-dependent model provides an accurate description of the change of slope (acceleration in water diffusion rate). It should be noted that the Fickian law that is presented in all these figures comes from an identification of 
the experimental data, based on the diffusion coefficient $\mathrm{D}$ identified in the linear part of the curve and the mass at saturation taken as the maximal water absorption. This is not the case for the proposed model, where each property is predicted based on the temperature and water activity of interest, providing a more accurate description of the water content at saturation in the range from 15 to $40^{\circ} \mathrm{C}$.

The water absorption in the amorphous phase of polyamide 6 follows a complex behaviour. The large water absorption induced by the presence of polar groups leads to significant plasticisation (decrease of more than $70^{\circ} \mathrm{C}$ in $\mathrm{T}_{\mathrm{g}}$ ). The latter increases the chain mobility inside the amorphous phase of the polymer and decreases the glass transition temperature. When the $T_{g}$ decreases to a value lower than the test temperature, the polymer changes into the rubbery state, which increases the specific volume of the polymer. This increase in volume results in an increase in diffusivity. Moreover, at high activities, the water uptake results in the formation of clusters that increase the maximal water absorption at a given water activity even more (deviation from Henry's law). Each of these complex behaviours has been accurately described, leading to a prediction for the water diffusion in a thick specimen exposed to a given temperature in the range from 15 to $40^{\circ} \mathrm{C}$.

However, some limits for this model can be noted. For instance, Figure 12.d shows a small difference concerning the predicted water content at saturation compared to the experimental data at $60^{\circ} \mathrm{C}$. The maximum water absorption is associated with the formation of clusters during water absorption, as presented in equation 6 . In this paper, $\mathrm{b}$ and $\mathrm{m}$ were taken to be material parameters independent of the temperature, which may not be valid over a wider range of temperature, in particular at high temperature and below $15^{\circ} \mathrm{C}$. Additional identification of these parameters would be needed to extend the range of application of the model. 


\section{Conclusion}

Water absorption in polyamide 6 has been considered in this study. The aim was to be able to model the water diffusion in thick specimens immersed in sea water. First, it has been shown that when PA6 is immersed either in seawater or in deionised water, it is not possible to model the water uptake accurately using simple Fickian behaviour. This is explained by the fact that the water diffusivity is not constant with the water content. Therefore, DVS measurements have been performed with small humidity steps $(5 \%)$ in order to characterise both the water content and the water diffusion coefficient. Results were described with mathematical equations related to physical processes (cluster formation, free volume theory) in order to propose a new diffusion model. This new model considers first the local water content in the polymer that depends on the surrounding environment. From this local water content, it is possible to evaluate the local $\mathrm{T}_{\mathrm{g}}$. Then, two cases are possible; if the polymer is in the glassy state $\left(\mathrm{T}<\mathrm{T}_{\mathrm{g}}\right)$, the diffusion coefficient $\mathrm{D}$ only depends on the temperature and can be described using an Arrhenius law. However, if the polymer is in the rubbery state $\left(\mathrm{T}>\mathrm{T}_{\mathrm{g}}\right)$, D depends on both the temperature and the water content. It has been shown that the latter can be accurately described in the temperature range from 15 to $40^{\circ} \mathrm{C}$ with the free volume theory. This new model has been used to predict the water absorption in a thick specimen immersed in sea water at different temperatures. Results show good agreement between the model and the experimental data, the predictions are significantly better than those based on Fickian behaviour. It is now possible to extend this study to evaluate the changes in mechanical properties of thick samples used for applications in a marine environment, and this work is underway.

\section{Acknowledgements}

The authors acknowledge the contribution of the Carnot Institutes IFREMEREDROME and CETIM for funding part of this study. 


\section{References}

[1] E. Naveau, Z. Dominkovics, C. Detrembleur, C. Jérôme, J. Hári, K. Renner, M. Alexandre, and B. Pukánszky, 'Effect of clay modification on the structure and mechanical properties of polyamide-6 nanocomposites', Eur. Polym. J., vol. 47, no. 1, pp. 5-15, Jan. 2011.

[2] H. Diao, P. Robinson, M. R. Wisnom, and A. Bismarck, 'Unidirectional carbon fibre reinforced polyamide-12 composites with enhanced strain to tensile failure by introducing fibre waviness', Compos. Part Appl. Sci. Manuf., vol. 87, pp. 186-193, Aug. 2016.

[3] D. Teixeira, M. Giovanela, L. B. Gonella, and J. S. Crespo, 'Influence of injection molding on the flexural strength and surface quality of long glass fiber-reinforced polyamide 6.6 composites', Mater. Des., vol. 85, pp. 695-706, Nov. 2015.

[4] O. Okamba-Diogo, E. Richaud, J. Verdu, F. Fernagut, J. Guilment, and B. Fayolle, 'Molecular and macromolecular structure changes in polyamide 11 during thermal oxidation', Polym. Degrad. Stab., vol. 108, pp. 123-132, Oct. 2014.

[5] P. Gijsman, W. Dong, A. Quintana, and M. Celina, 'Influence of temperature and stabilization on oxygen diffusion limited oxidation profiles of polyamide 6', Polym. Degrad. Stab., vol. 130, pp. 83-96, Aug. 2016.

[6] L. Silva, S. Tognana, and W. Salgueiro, 'Study of the water absorption and its influence on the Young's modulus in a commercial polyamide', Polym. Test., vol. 32, no. 1, pp. 158-164, Feb. 2013.

[7] L.-T. Lim, I. J. Britt, and M. A. Tung, 'Sorption and transport of water vapor in nylon 6,6 film', J. Appl. Polym. Sci., vol. 71, no. 2, pp. 197-206, Jan. 1999.

[8] H. K. Reimschuessel, 'Relationships on the effect of water on glass transition temperature and young's modulus of nylon 6', J. Polym. Sci. Polym. Chem. Ed., vol. 16, no. 6, pp. 1229-1236, Jun. 1978.

[9] C. El-Mazry, O. Correc, and X. Colin, 'A new kinetic model for predicting polyamide 66 hydrolysis and its mechanical embrittlement', Polym. Degrad. Stab., vol. 97, no. 6, pp. 1049-1059, Jun. 2012.

[10] R. Bernstein and K. T. Gillen, 'Nylon 6.6 accelerating aging studies: II. Long-term thermal-oxidative and hydrolysis results', Polym. Degrad. Stab., vol. 95, no. 9, pp. 1471-1479, Sep. 2010.

[11] R. Bernstein, D. K. Derzon, and K. T. Gillen, 'Nylon 6.6 accelerated aging studies: thermal-oxidative degradation and its interaction with hydrolysis', Polym. Degrad. Stab., vol. 88, no. 3, pp. 480-488, Jun. 2005.

[12] N. Abacha, 'Diffusion behavior of water in polyamide 6 organoclay nanocomposites', Express Polym. Lett., vol. 3, no. 4, pp. 245-255, Mar. 2009.

[13] J. Hanspach and F. Pinno, 'Concentration dependent diffusion of water in polyamide 6', Acta Polym., vol. 43, no. 4, pp. 210-213, Aug. 1992.

[14] T. Asada and S. Onogi, 'The diffusion coefficient for the nylon 6 and water system', $J$. Colloid Sci., vol. 18, no. 8, pp. 784-792, Oct. 1963.

[15] E. Picard, J.-F. Gérard, and E. Espuche, 'Water transport properties of polyamide 6 based nanocomposites prepared by melt blending: On the importance of the clay dispersion state on the water transport properties at high water activity', J. Membr. Sci., vol. 313, no. 1-2, pp. 284-295, Apr. 2008.

[16] F.-M. Preda, A. Alegría, A. Bocahut, L.-A. Fillot, D. R. Long, and P. Sotta, 'Investigation of Water Diffusion Mechanisms in Relation to Polymer Relaxations in Polyamides', Macromolecules, vol. 48, no. 16, pp. 5730-5741, Aug. 2015. 
[17] M. Broudin, P. Y. Le Gac, V. Le Saux, C. Champy, G. Robert, P. Charrier, and Y. Marco, 'Water diffusivity in PA66: Experimental characterization and modeling based on free volume theory', Eur. Polym. J., vol. 67, pp. 326-334, Jun. 2015.

[18] D. W. van Krevelen and K. te Nijenhuis, Properties of Polymers: Their Correlation with Chemical Structure; their Numerical Estimation and Prediction from Additive Group Contributions. Elsevier, 2009.

[19] R. A. Robinson, 'The vapour pressure and osmotic equivalence of sea water', J. Mar. Biol. Assoc. U. K., vol. 33, no. 2, pp. 449-455, Jun. 1954.

[20] J. Crank, The mathematics of diffusion, 2d ed. Oxford, [Eng]: Clarendon Press, 1975.

[21] N. J. W. Reuvers, H. P. Huinink, H. R. Fischer, and O. C. G. Adan, 'The influence of ions on water transport in nylon 6 films', Polymer, vol. 54, no. 20, pp. 5419-5428, Sep. 2013.

[22] P. Y. Le Gac, G. Roux, P. Davies, B. Fayolle, and J. Verdu, 'Water clustering in polychloroprene', Polymer, vol. 55, no. 12, pp. 2861-2866, Jun. 2014.

[23] X. Colin and J. Verdu, 'Humid Ageing of Organic Matrix Composites', in Durability of Composites in the Marine Environment, Springer Netherlands., vol. 208, 2014, pp. 47114.

[24] M. Broudin, V. Le Saux, P. Y. Le Gac, C. Champy, G. Robert, P. Charrier, and Y. Marco, 'Moisture sorption in polyamide 6.6: Experimental investigation and comparison to four physical-based models', Polym. Test., vol. 43, pp. 10-20, May 2015.

[25] F. N. Kelley and F. Bueche, 'Viscosity and glass temperature relations for polymerdiluent systems', J. Polym. Sci., vol. 50, no. 154, pp. 549-556, Apr. 1961.

[26] J. S. Vrentas and J. L. Duda, 'Diffusion in polymer-solvent systems. I. Reexamination of the free-volume theory', J. Polym. Sci. Polym. Phys. Ed., vol. 15, no. 3, pp. 403-416, 1977.

[27] J. S. Vrentas and J. L. Duda, 'Diffusion in polymer-solvent systems. II. A predictive theory for the dependence of diffusion coefficients on temperature, concentration, and molecular weight', J. Polym. Sci. Polym. Phys. Ed., vol. 15, no. 3, pp. 417-439, 1977.

[28] S.-U. Hong, 'Prediction of polymer/solvent diffusion behavior using free-volume theory', Ind. Eng. Chem. Res., vol. 34, no. 7, pp. 2536-2544, 1995. 
Table 1 : Values for Water, from [28]

\begin{tabular}{|c|c|}
\hline Constant & Value \\
\hline$\widehat{V_{1}^{*}}$ & 1.071 \\
\hline$\frac{K_{11}}{\gamma}$ & $2.18 \times 10^{3}$ \\
\hline$K_{21}-T_{g 1}$ & -152.3 \\
\hline
\end{tabular}

Table 2 : Values for the polymer, from [18]

\begin{tabular}{|c|c|}
\hline Constant & Value \\
\hline $\mathrm{C}_{1}$ & 17 \\
\hline $\mathrm{C}_{2}$ & 51 \\
\hline$\widehat{V_{2}^{*}}$ & 0,935 \\
\hline
\end{tabular}




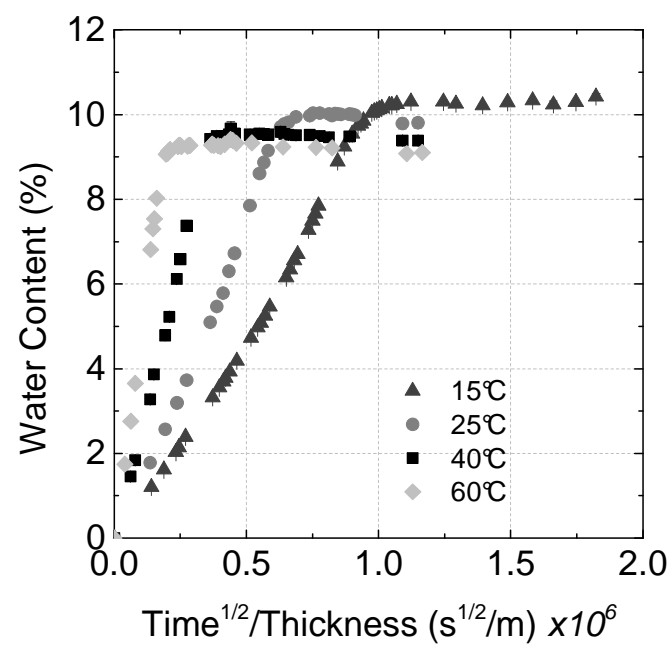

(a)

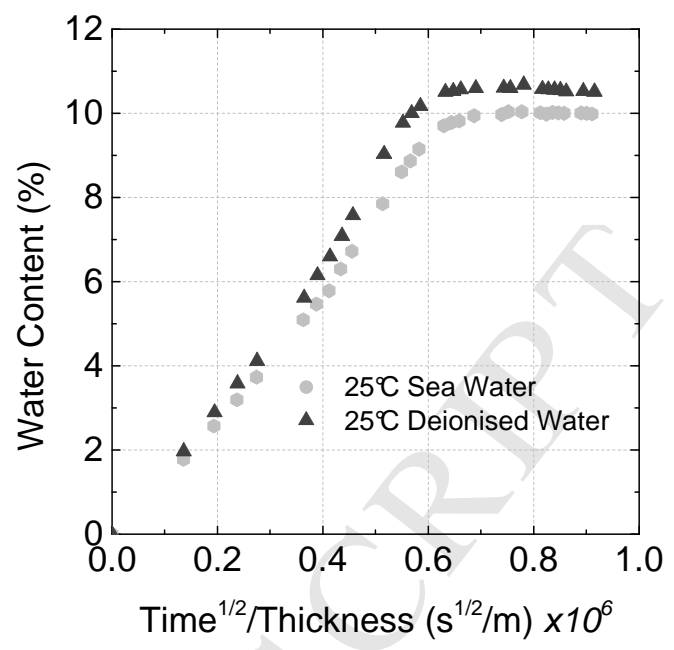

(b)

Figure 1 : (a) Water absorption in PA 6 immersed in sea water at several temperature (b) Effect of water type on $2 \mathrm{~mm}$ thick specimens at $25^{\circ} \mathrm{C}$

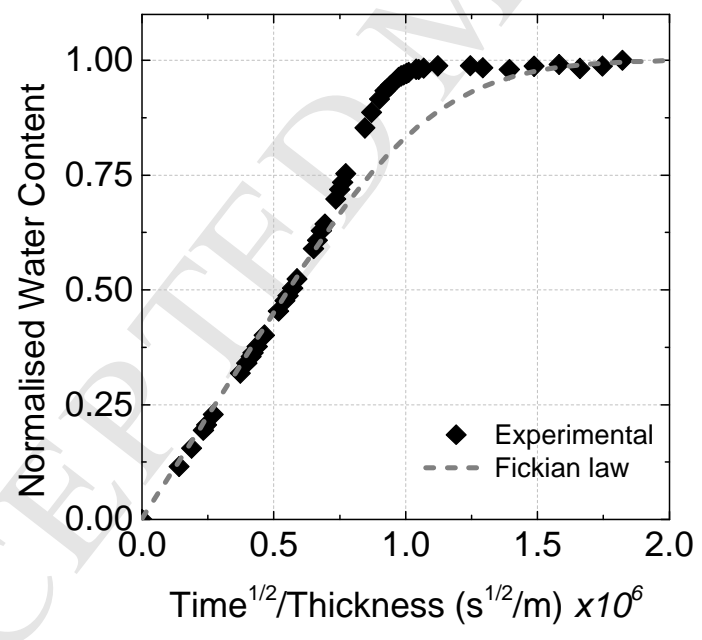

Figure 2 : Comparison between experimental results at $15^{\circ} \mathrm{C}$ in sea water and a Fickian behaviour with a D equal to $1.6 \times 10^{-13} \mathrm{~m}^{2} / \mathrm{s}$ (identified on the experimental data in the linear part of the sorption curve) 


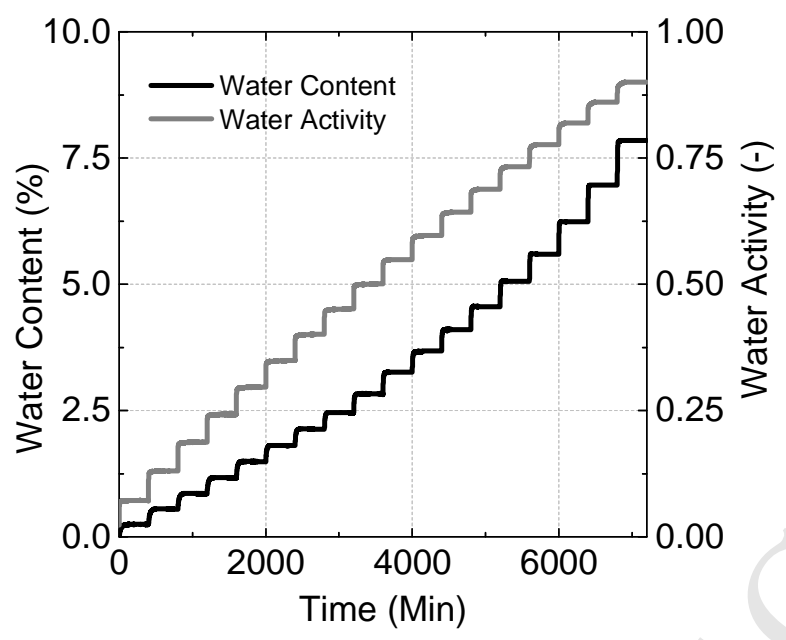

Figure 3 : Typical water absorption at $40^{\circ} \mathrm{C}$ as a function of water activity

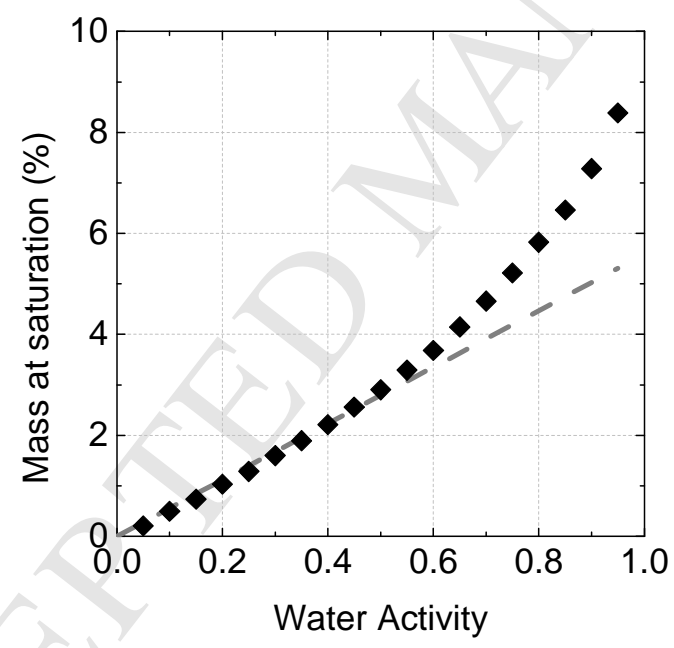

Figure 4 : Changes in the amount of absorbed water as a function of water activity at $25^{\circ} \mathrm{C}$ 


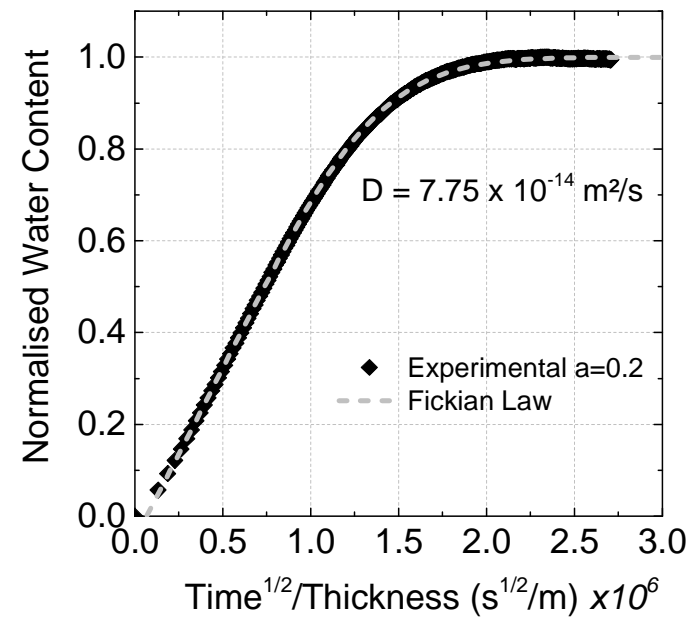

(a)

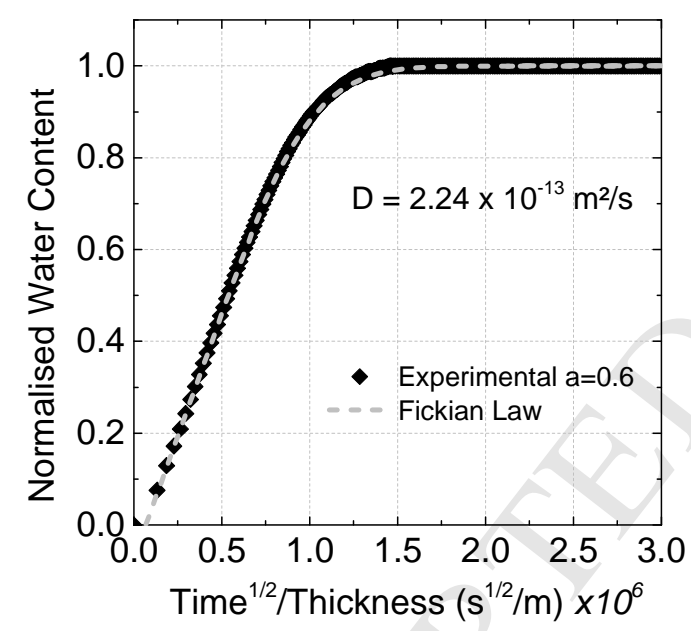

(c)

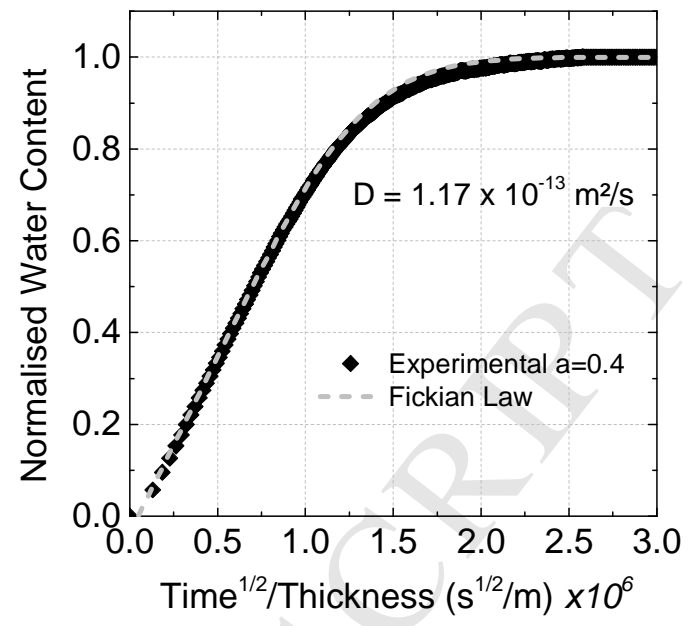

(b)

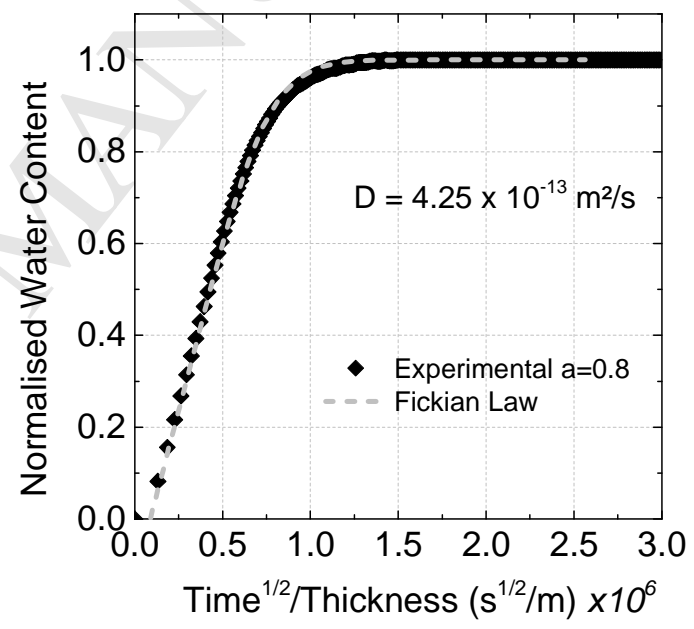

(d)

Figure 5 : Normalized water absorption at $25^{\circ} \mathrm{C}$ as a function of water activity (a) a $=0.2$ (b)

$$
\mathrm{a}=0.4 \text { (c) } \mathrm{a}=0.6 \text { (d) } \mathrm{a}=0.8
$$




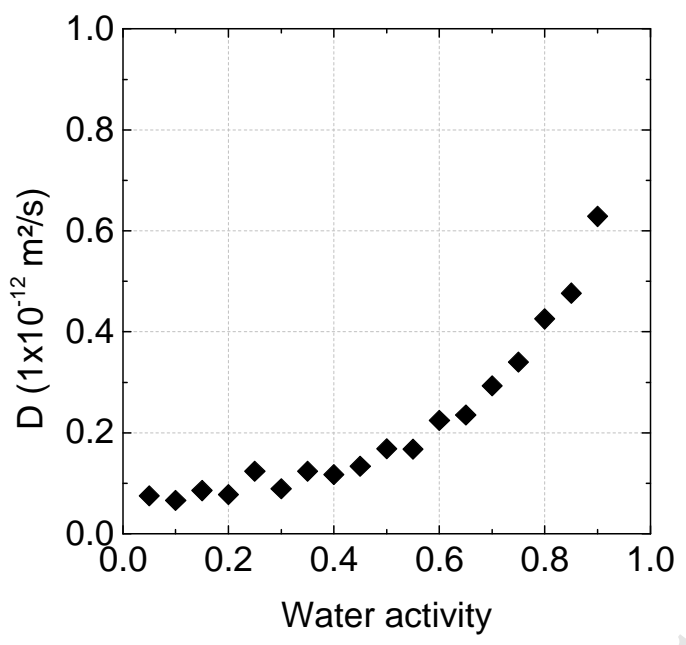

Figure 6 : Change in diffusivity as function of water activity in PA 6 (example at $25^{\circ} \mathrm{C}$ )

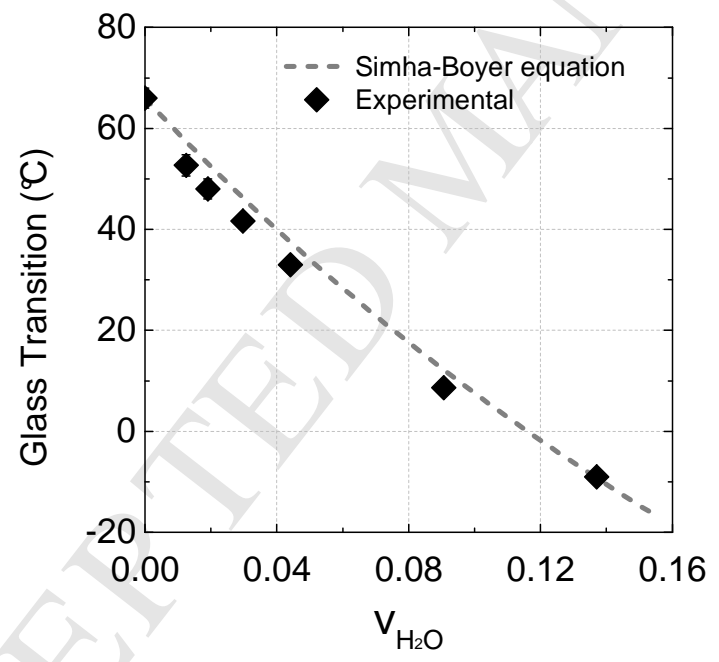

Figure 7 : Changes in $\mathrm{T}_{\mathrm{g}}$ with water content measured (points) and predicted (dotted line) 


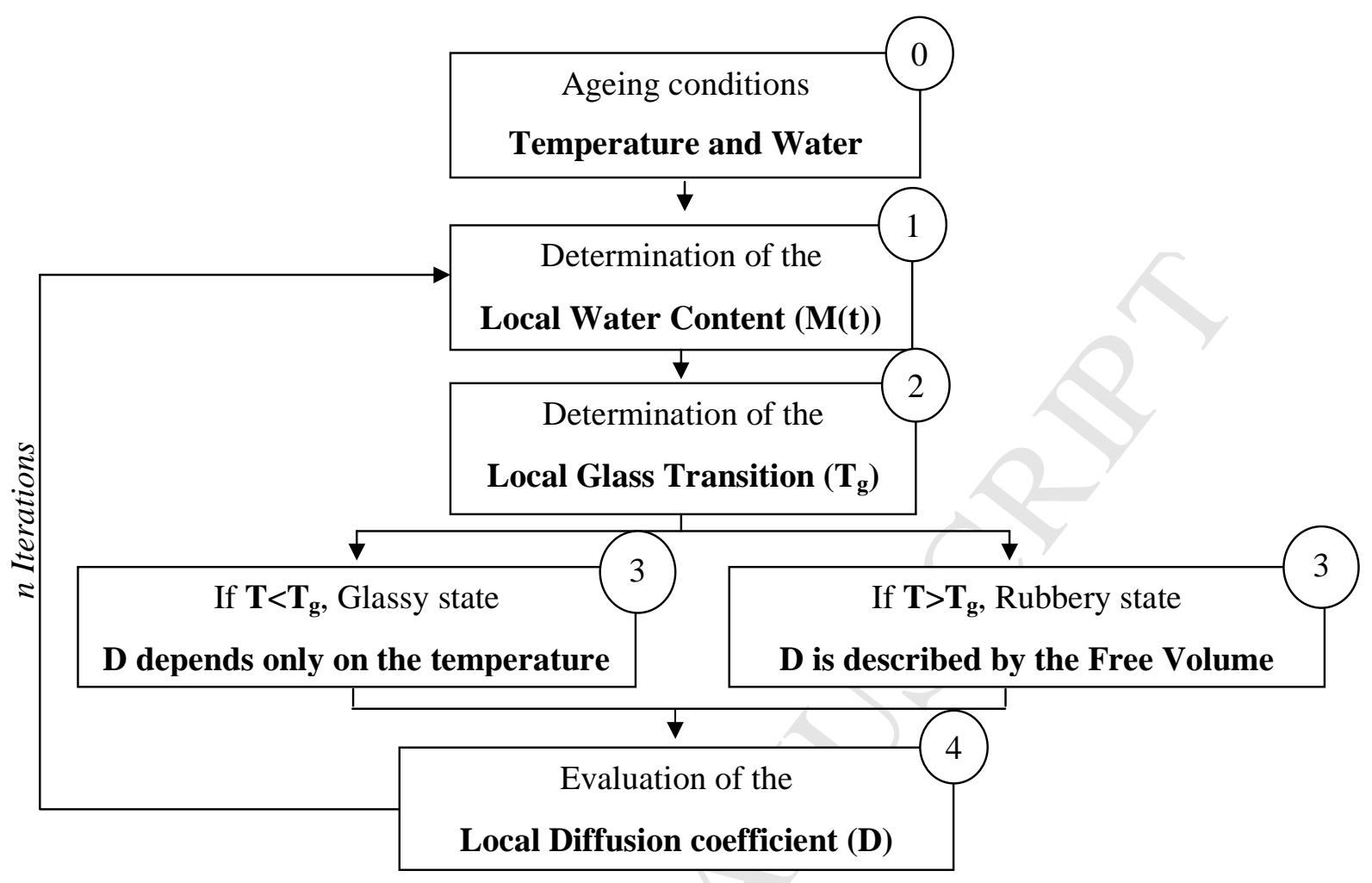

Figure $8:$ Schematic representation of the model

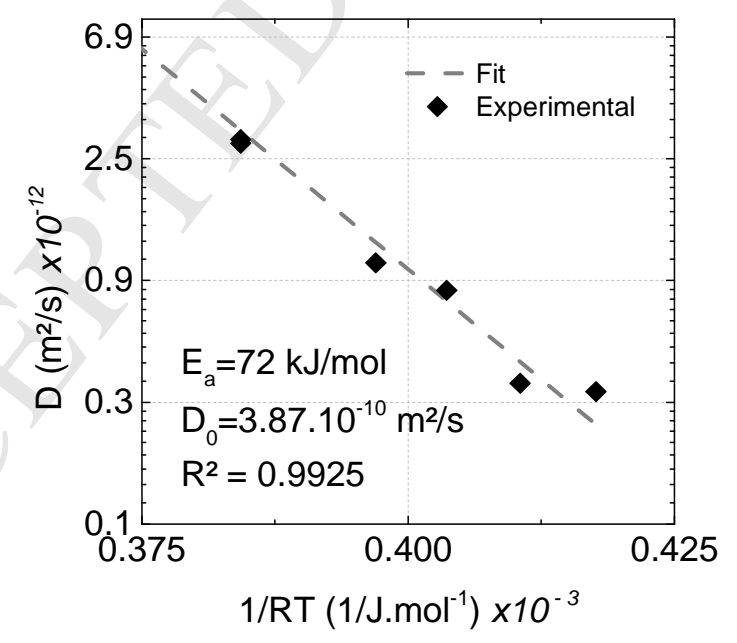

Figure 9 : Measured diffusion coefficient $\mathrm{D}$ as a function of 1/RT 


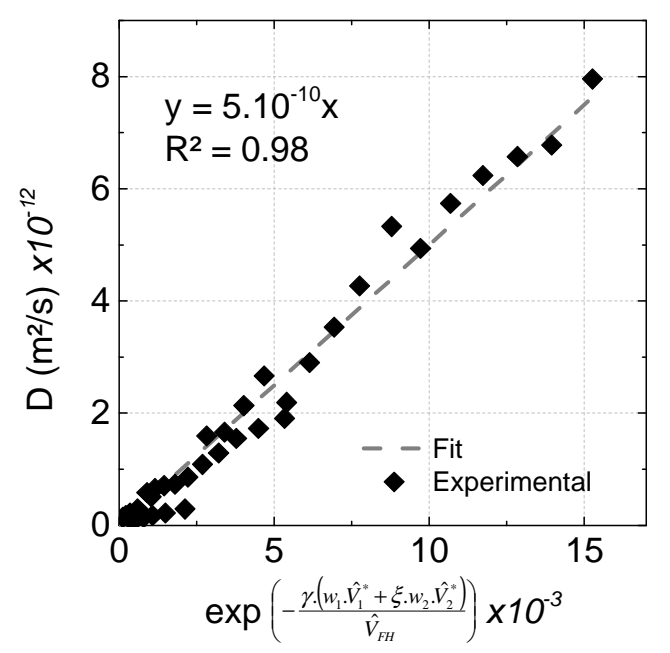

Figure 10 : Experimental values of $\mathrm{D}$ as a function of the exponential term

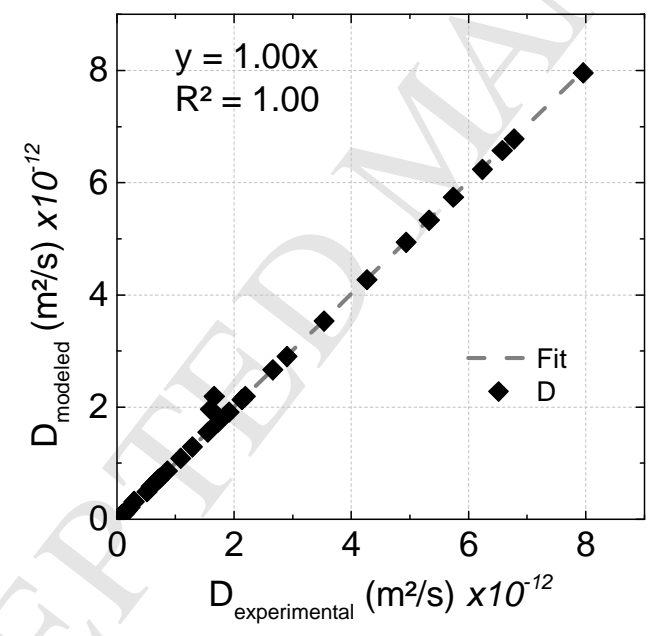

Figure 11 : Predicted diffusion coefficient versus the measured values of D. 


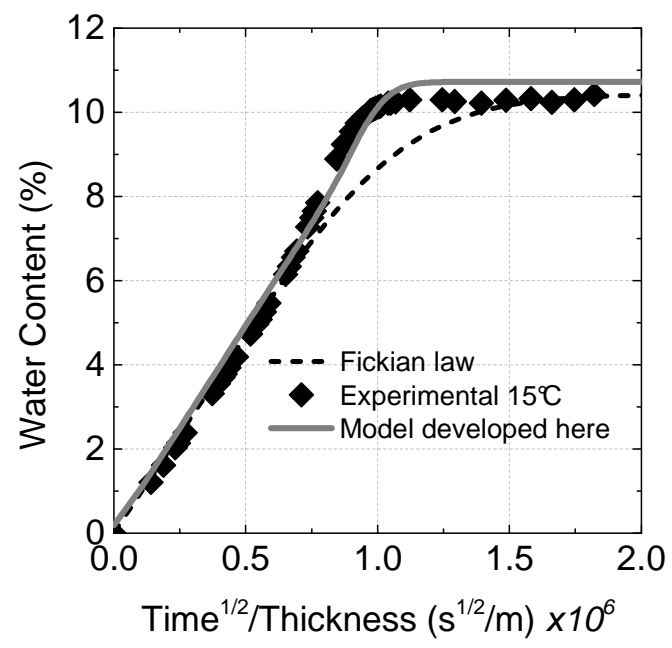

(a)

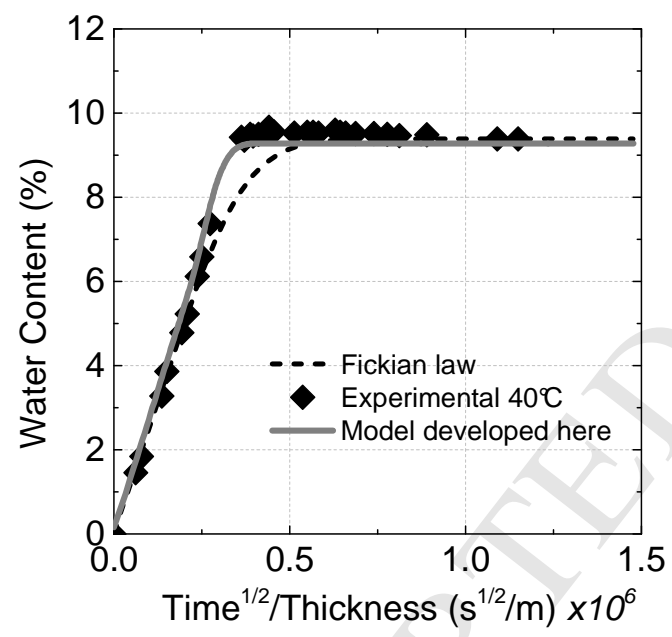

(c)

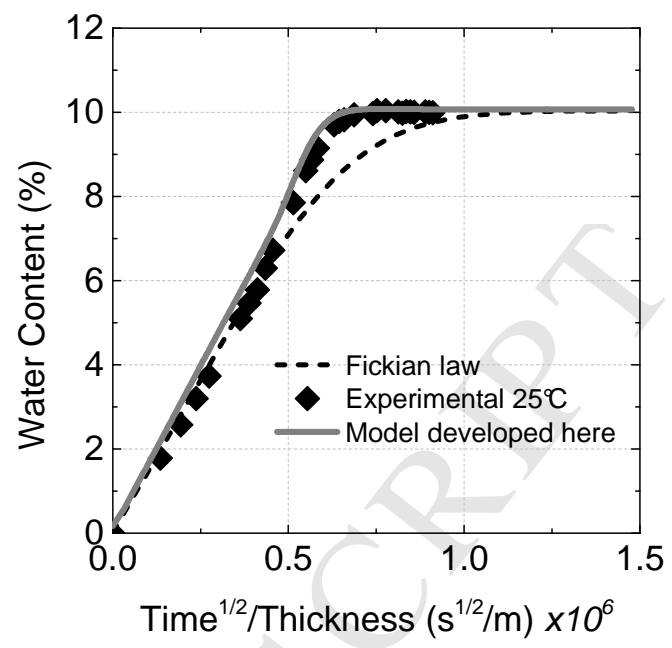

(b)

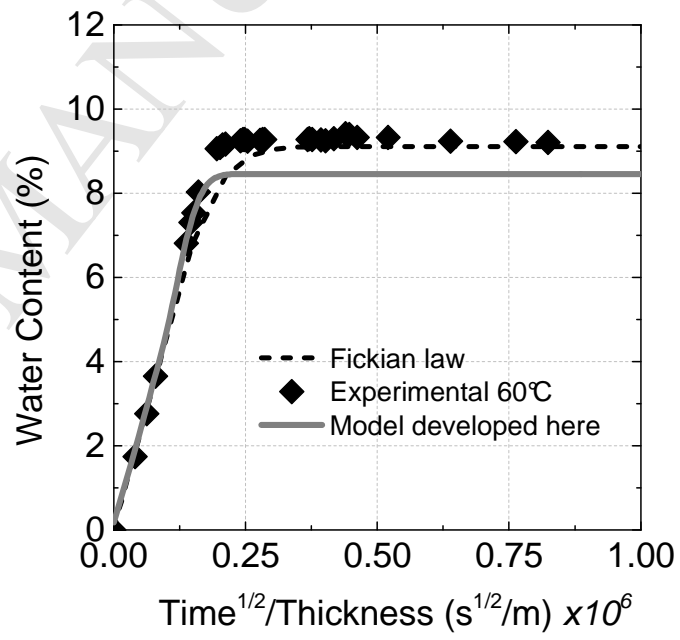

(d)

Figure 12 : Comparison between experimental results obtained on $2 \mathrm{~mm}$ thick samples immersed in sea water and the specific model developed in this study as well as the Fickian equivalent for (a) $15^{\circ} \mathrm{C}$ (b) $25^{\circ} \mathrm{C}$ (c) $40^{\circ} \mathrm{C}$ (d) $60^{\circ} \mathrm{C}$ 